Portland State University

PDXScholar

2-8-1998

\title{
The Effectiveness of Hypermedia Training vs. Traditional Classroom Instruction in Stuttering
}

\author{
Micheal Dean Baran \\ Portland State University
}

Follow this and additional works at: https://pdxscholar.library.pdx.edu/open_access_etds

Part of the Speech and Hearing Science Commons

Let us know how access to this document benefits you.

\section{Recommended Citation}

Baran, Micheal Dean, "The Effectiveness of Hypermedia Training vs. Traditional Classroom Instruction in Stuttering" (1998). Dissertations and Theses. Paper 5821.

https://doi.org/10.15760/etd.7692

This Thesis is brought to you for free and open access. It has been accepted for inclusion in Dissertations and Theses by an authorized administrator of PDXScholar. Please contact us if we can make this document more accessible: pdxscholar@pdx.edu. 


\section{THESIS APPROVAL}

The abstract and thesis of Michael Dean Baran for the Master of Science in

Speech Communication: Speech and Hearing Science were presented

February 9, 1998, and accepted by the thesis committee and the department.

COMMITTEE APPROVALS:

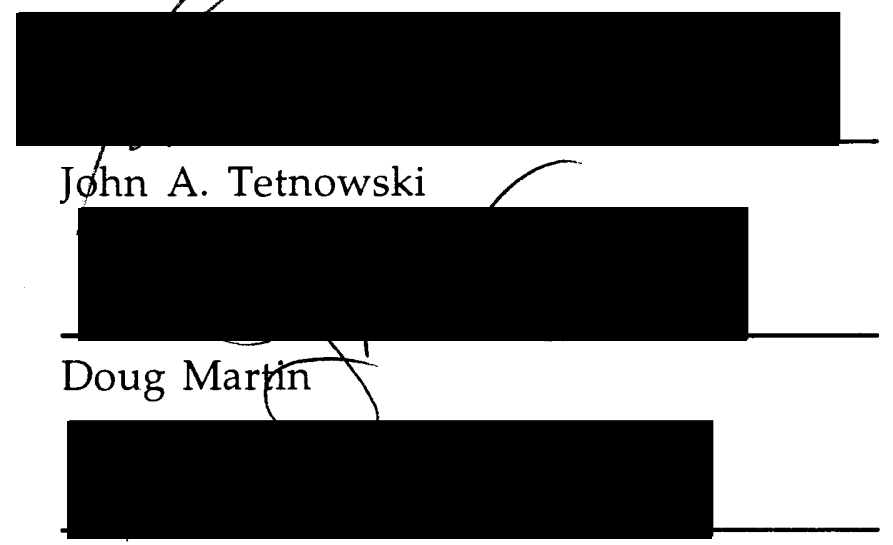

Carrol Tama

DEPARTMENT APPROVAL:

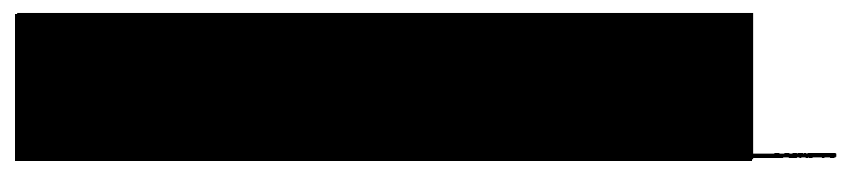

Peter Ehrenhaus, Acting Chair

Department of Speech Communication 


\begin{abstract}
An abstract of the thesis of Michael Dean Baran for the Master of Science in Speech Communication: Speech and Hearing Science presented on February 9, 1998.
\end{abstract}

Title: The Effectiveness of Hypermedia Training vs. Traditional Classroom Instruction in Stuttering

A study by Henri (1994) showed that fluency is one of two areas where speech-language pathology clinicians feel least prepared and Sommers and Caruso (1995) advocated improved training in fluency. The use of computer technology to train students in the field of stuttering has been proven effective in previous studies (Strang, Meyers \& Hall, 1989; Tetnowski \& Martin, 1996).

The purpose of this study was to further develop a hypermedia training module for stuttering identification and to determine whether this hypermedia training module was as effective as traditional classroom teaching methods.

Subjects in this study were undergraduate students in speech and hearing sciences currently enrolled in the Disorders of Communication II course at Portland State University. Subjects were randomly placed into one of two groups, hypermedia training or traditional classroom instruction. Following elimination criteria, the data for 13 subjects participating in the hypermedia group and 15 subjects in the traditional classroom instruction group were analyzed.

A hypermedia training program was developed from the outline 
normally used for instruction of the class. Subjects in the hypermedia training group were provided with access to the program for a one week period while subjects in the classroom instruction group received five hours of direct instruction over three class periods.

In the post-testing phase subjects from both groups observed a videotaped speech sample and marked all occurrences of stuttering. Every word (unit) selected by each subject was compared for whether it was stuttered/not stuttered with the unanimous selections made by a panel of three experienced and certified speech-language pathologists (SLP's) with experience in stuttering.

A total number of unit-by-unit agreements for each subject and group was calculated. An unequal variance t-test was performed in order to determine if hypermedia training of a stuttering identification task was as effective as traditional classroom instruction methods. Results showed a significant difference $(t=3.89, p=.0016)$ between the scores of subjects trained through the hypermedia training program and through traditional classroom instruction methods at the .05 alpha level. In this study, hypermedia training was found to be a more effective instructional method. 
THE EFFECTIVENESS OF HYPERMEDIA TRAINING

VS.

TRADITIONAL CLASSROOM INSTRUCTION IN STUTTERING

by

MICHAEL DEAN BARAN

A thesis submitted in partial fulfillment of the requirements for the degree of

\author{
MASTER OF SCIENCE \\ in \\ SPEECH COMMUNICATION: \\ SPEECH AND HEARING SCIENCE
}

Portland State University

1998 


\section{TABLE OF CONTENTS}

ITEM

$\underline{\text { PAGE }}$

LIST OF TABLES

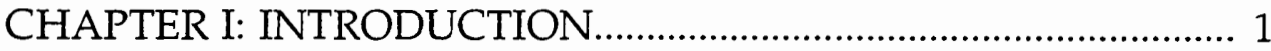

Definition of Terms............................................................... 3

CHAPTER II: REVIEW OF THE LITERATURE................................ 6

Hypermedia in Speech Communication................................ 6

Stuttering Identification............................................................ 11

Basis For Improved Fluency Training.................................... 14

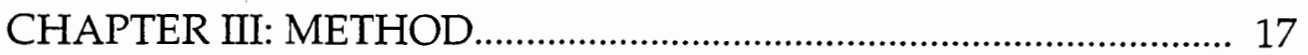

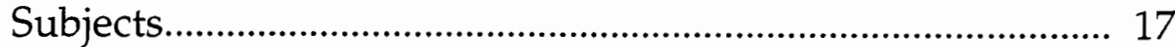

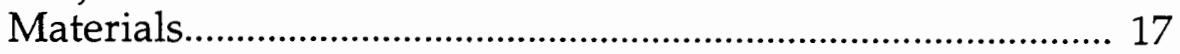

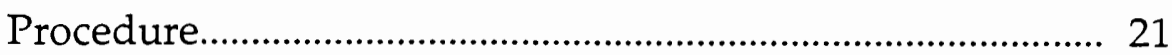

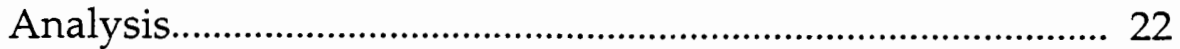

CHAPTER IV: RESULTS AND DISCUSSION ............................... 24

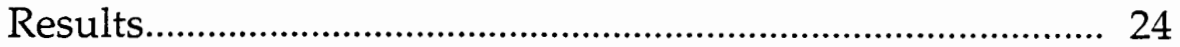

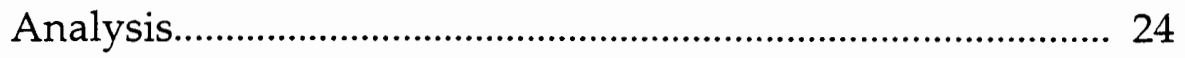

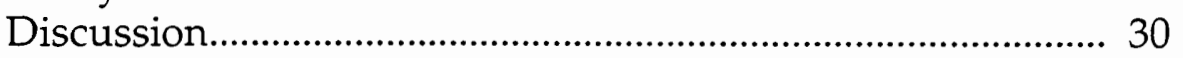

CHAPTER V: SUMMARY AND IMPLICATIONS........................... 33

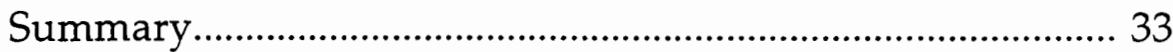

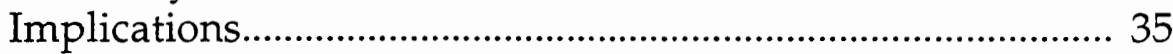

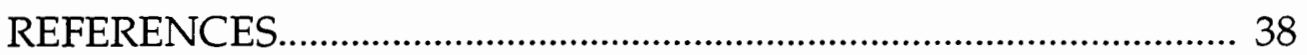

APPENDICES

A Stuttering Identification Post-Testing Passage............. 43

B Subject Questionnaire...................................................... 44 


\section{LIST OF TABLES}

TABLE

$\underline{\text { PAGE }}$

1 Improvements To Stuttering Identification

Program For Current Research Study....................................... 21

2 Group Data Comparison...................................................... 25

3 Subject Data For Hypermedia Training Group..................... 28

4 Subject Data For Traditional Classroom

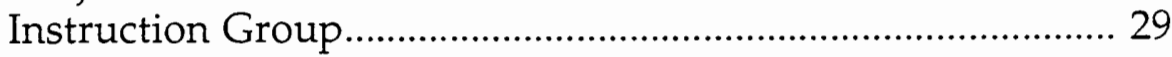




\section{CHAPTER I}

\section{INTRODUCTION}

Many studies illustrate the poor reliability of stuttering identification among judges (Cordes, Ingham, Frank \& Ingham, 1992; Coyle \& Mallard, 1979; Curlee, Perkins, \& Michael, 1970; Curlee, 1981; Emerick, 1960; Ham, 1989; Ingham \& Cordes, 1992; Kully \& Boberg, 1988; MacDonald \& Martin, 1973; Young, 1975, 1984). Cordes and Ingham (1994) state that "substantial differences among judges are consistently demonstrated, but the factors that might influence those differences are only beginning to be explored" (p. 284). Data from Curlee's (1981) study, which used graduate and undergraduate students as subjects, supports this belief. It was found that "there was relatively low unit-by-unit agreement among listeners" (p. 595). According to Ingham, Cordes, Ingham and Gow (1995) "training procedures must be developed if the data that form the basis of ongoing investigations into the nature and treatment of stuttering are to be reliable and valid" (p. 325).

The identification of stuttering is one of several areas in which individuals may benefit from instruction through hypermedia training programs. While the use of hypermedia training in the field of speechpathology and audiology is increasing, little research is being devoted to fluency (Strang \& Meyers, 1987; Strang, Meyers \& Hall, 1989). In order to address the need for better accuracy in stuttering identification tasks, development of a hypermedia training program may be able to provide the field of speech and hearing sciences with a solution to a problem which has stymied researchers and clinicians alike for the better part of the 20th century. 
The determination of "What is stuttering?" is still under debate among researchers in the field of speech and hearing sciences (Ingham, 1990; Moore \& Perkins, 1990; Perkins, 1990) and as yet, the determination remains unresolved. Perkins (1990) believes that stuttering is a private event that can only be determined by the speaker while others (Ingham, 1990) believe that stuttering is determined by the perceptions of independent observers. The debate about whether stuttering events are private events or observed disruptions will likely continue in the years to come, but either way, it is important that we continue to look at new ways of identifying stuttering events regardless of who is performing the judging.

This research study follows that of Tetnowski and Martin (1996) in that the instructor and contributor of content remain the same and the study is being conducted at the same university. Aside from this, the present study will provide further data on the effectiveness of hypermedia training as an instructional method for educating undergraduate students. There are several key differences between this study and that conducted by Tetnowski and Martin (1996). In addition to many key changes being made to the hypermedia program in order to provide subjects with a more interactive education tool, this study looks at the use of instructional methods with undergraduate students instead of graduate students and will utilize a larger sample size than that of the previous study.

The null hypothesis of this study is that, "No significant difference exists in the scores between students instructed through hypermedia 
training or through traditional classroom instruction methods." If the null hypothesis fails to be rejected, one may conclude that within the scope of this one study, hypermedia was found to be an effective means of educating undergraduate students in stuttering identification. Thus, the purpose of this study is to further develop a hypermedia training module for stuttering identification and to determine whether this hypermedia training module is as effective as traditional classroom instruction methods.

\section{Definition of Terms}

The following terms used throughout this study are more specifically defined below.

Fixations: a prolongation or maintenance of an articulatory or phonatory posture for an abnormal duration; another name for a stoppage and one of the four disfluency types commonly considered to be stuttering.

Fluency: according to Nicolosi, Harryman and Kresheck (1996) fluency is the "smoothness with which sounds, syllables, words, and phrases are joined together during oral language: lack of hesitations or repetitions in speaking." A fluency disorder is a term used to "describe any interruption in the flow of oral language and/or deviations from acceptable rhythm of speech noticeable enough to cause concern."

Hypermedia: according to Liu and Reed (1994) it "refers to an associative, nonlinear information presentation and representation system built around a network of multimedia materials such as text, graphics, sound, animation, and motion" (p. 421). 
Normal pauses: hesitancies or breaks in the forward flow of speech that are produced without tension. This type of disfluency is not typically considered to be stuttering.

Prolongations: the lengthening of a speech sound or maintaining the posture of the lips, tongue, or other parts of the speech mechanism in an attempt to modify the stuttering pattern; one of the four disfluency types commonly considered to be stuttering.

Repetition of one syllable words: a type of disfluency where the speaker repeats a single syllable word repeatedly. There is some disagreement among experts, but the majority consider this behavior to be indicative of stuttering.

Rephrasing of a sentence: a type of disfluency where the speaker begins a sentence, hesitates, and then rephrases the intended thought. This type of disfluency is not typically considered to be stuttering.

Repetition of phrases: a type of disfluency where the speaker repeats a part of a phrase or the entire phrase more than once in succession. This type of disfluency is not typically considered to be stuttering.

Stoppages: a prolongation or maintenance of an articulatory or phonatory posture for an abnormal duration; another name for a fixation and one of the four disfluency types commonly considered to be stuttering

Stuttering: a fluency disorder typically characterized by sound repetitions, prolongations, and/or stoppages of sound. The previously mentioned behaviors are the outward manifestations of the disorder; however, covert symptoms related to tension, stress and fear can also be 
part of this disorder.

Stuttering Severity Instrument for Children and Adults (SSI): one of the commonly "standardized" measures for rating stuttering severity. This tool was developed by Glyndon Riley. The most recent revision of this tool, the 3rd edition, was released in 1994.

Unit-by-unit identification: a method where each individual word or syllable is evaluated for the presence/absence of stuttering.

Videosound spectrogram: refers to the actual display from a digital electronic device which is used to store, sample, and analyze the speech signal. The spectrogram can be shown as a continuous time-by-frequency spectrogram or as one or more spectral plots taken at specific moments. The videosound spectrogram can provide fundamental frequency of voice, duration of segments of speech or intervals between segments of interest, approximate location of vocal tract resonance (formants of speech), and approximate measures of intensity. 


\section{CHAPTER II \\ REVIEW OF THE LITERATURE}

\section{Hypermedia in Speech Communication}

Hughes, Lehman, Scukanec, \& Tatchell (1993) state, "several courses in the curriculum (Speech Communication) lend themselves to computerassisted instruction both in and outside class" (p. 38). They mention anatomy, neuroanatomy, phonetics and speech science, although more could be added to this list. Several studies will be discussed in this section which have used hypermedia in other areas of speech communication, but besides a recent study by Tetnowski and Martin (1996), little research has been completed which has investigated the use of hypermedia as a tool for training students in stuttering identification.

The use of computer technology to train student-clinicians in other areas of stuttering has been proven effective in previous studies. In a study by Strang et al. (1989), the authors used twenty graduate students enrolled in an introductory fluency course as subjects. In this study, the authors used a computerized training program that allowed the subjects to carry on a real-time dialogue with a young child in preschool who stuttered. The stuttering level of the child was directly tied to the effectiveness of the student-clinician's intervention. The authors found that the group of subjects who received more training using the software used significantly more effective and significantly fewer ineffective intervention techniques.

The advent of multimedia programs began in the 1970's, and their use as an instructional method has slowly grown. In recent years, research 
has validated its effectiveness as a viable instructional method which has resulted in more research being done in this area. Perhaps, the unit-byunit identification of a stuttering event is an area within the field of speech communication which could benefit from the use of hypermedia technology as a training tool.

One recent study which showed the effectiveness of using multimedia as an instructional method indicated that students learning Developmental Sentence Scoring (DSS) (Lee, 1974) through either computer-assisted instruction or traditional methods achieved equal mastery levels (Hughes, Fey, Kertoy, \& Nelson, 1993). In addition, the computer-assisted instruction method only required one-seventh the instructional time. This study supports the educational advantage of utilizing current technologies to supplement traditional learning strategies.

Ott-Rose and Cochran (1992) compared the computer-controlled videodisc and traditional picture stimuli methods in teaching action verbs. They found that many action verbs do not lend themselves well to realistic demonstration through the actions of the clinician or manipulation of objects. As a clinician, when choosing between pictures and objects you may be making a choice between what they termed "two evils". They felt that pictures were effective at providing context and are effective for teaching verbs which are often difficult to demonstrate, but they are not an extremely effective stimuli. Whereas, objects may be an effective stimuli, but if the clinician does not act upon the object in a way that is familiar to the child, it would not be realistic to that child. Their study found that both 
instructional methods were effective, but that four of the five children did as well or better with the videodisc training and the one child who did better with the picture stimuli actually preferred learning with the videodisc training. It appears that in at least two recent studies, the subjects either preferred (MacArthur \& Haynes, 1995) or gave numerous positive comments (Tetnowski \& Martin, 1996) about the the computer-assisted instruction method.

According to Ingham et al. (1995), one of the distinct advantages videolaser disc technology has over other methods is not only the ability to provide the judges with audible features, but also the ability to provide visual access. Like videolaser disc technology, hypermedia technology provides the user with the ability to evaluate the event frame by frame as the samples are played. While hypermedia may not, at this time, offer the video quality and versatility of videolaser disc technology, it allows the user access to written text contained in links. Liu and Reed (1994) cited several areas where hypermedia offers distinct advantages over videolaser disc technology. These areas include nonlinearity, associativity, flexibility, and efficiency. Accessibility is another key issue as videolaser disc technology is not commonplace at this point in time; meanwhile, CD-ROM players can be found in nearly all schools, clinics, and hospitals and in many private practices. In addition, the ability to add links to definitions, and allow responses and feedback to the user in real-time is unique to hypermedia and is what makes it such an effective training tool, and thus, the one proposed in this study. 
Schery and O'Connor (1992) stated that it is important to determine whether hypermedia technology can be used more extensively in instruction. They found that of the fifty-two subjects in their study with mental retardation, those who received school-based computer language intervention made greater gains than the group receiving traditional classroom instruction. Although the majority of the students required assistance while working on the computer, these individuals made dramatic progress in their speech and language development. The authors of this study noted the case of a non-verbal four-year old, with a prior diagnosis of autism and mental retardation, who began to echo words for the first time while using the computer. It appears that computer-assisted instruction can be helpful in many tasks which were traditionally done with classroom instruction.

One reason the effectiveness of hypermedia as an educational tool is starting to gain more attention from educators is that there have been several studies in the area of children's language which have demonstrated the effectiveness of hypermedia training. MacArthur and Haynes' (1995) longitudinal study showed that hypermedia was easy for students to learn and provided meaningful assistance in comprehension of content to those children who are language delayed. Their study, which observed 10 students with learning disabilities, aged 15 to 17 , showed that students received significantly higher comprehension scores when using an enhanced software program than when using a simpler version. The basic version included the components found in the current textbook used in 
the classroom, while the enhanced version added speech synthesis and links for questions.

Recent studies have shown that the use of hypermedia programs can be an effective instructional method for students. In Tetnowski and Martin's (1996) study, twenty graduate students in speech and hearing sciences, currently enrolled in a graduate stuttering course at Portland State University, were randomly assigned to one of two groups. The classroom instruction included lecture and pseudostuttering by the instructor, as well as videotape samples; while the hypermedia group received a written "how to" script, definitions, a script of reading or other speaking tasks, video samples of the children and adults, and practice items. The hypermedia group's program was stored on the hard drive of a Macintosh computer, and consisted of the aforementioned components integrated into an instructional program written by the authors.

The group receiving traditional classroom instruction received five hours of instruction, while the hypermedia instructed group received fifteen minutes of classroom instruction and then a self-determined amount of time to use the hypermedia training module. After this time, the groups were tested, using videotaped samples with pencil and paper. Their scores for the number of units of stuttering were compared with two "expert" judges, with at least ten years of experience who are instructors in the area of stuttering. The results showed there was no significant statistical difference between the two groups.

Tetnowski and Martin (1996) noted that instructing students in 
stuttering identification is time-consuming and that if the student began the class with this background knowledge, in-class time could be used for other course topics. Therefore, the authors hypothesized that computer technology could be a viable instructional method and would allow the instructor to provide competent clinical training without sacrificing classroom time.

Comments from the subjects in the hypermedia group included, "I liked working at my own pace.", "I'm glad that I could do the tasks over as many times as I liked.", although one subject stated that, "The videos could have been bigger." The authors felt that besides allowing for more class time to be spent on less repetitive tasks, hypermedia training promoted student independence and improved computer skills. These results indicate hypermedia may be an effective method for instructing students in stuttering identification.

\section{Stuttering Identification}

Most stuttering evaluations require a clinician to determine whether stuttering occurred, the length of the stuttering event, and the type of stuttering occurrence. These descriptors provide clinicians with valuable information that can be used in the diagnosis and treatment of fluency disordered clients. Despite questionable reliability between judges, this is still the most common measure used to evaluate stuttering behaviors. Very few studies have looked at training procedures specific to this task. The few studies that have explored this area have been summarized in this section. 
Agreements on when stuttering events occur has been a topic of interest and debate in the field of speech and hearing sciences as early as Tuthill's (1946) pioneering study. As current studies continue to be completed in this area, several researchers have investigated interjudge and intrajudge agreements of stuttering events. Research completed this decade (Cooper, 1990), has only further validated that of studies conducted previously (Young, 1975; Young 1984). The results indicate there is little agreement on the location and number of stuttering events among judges (Cordes et al., 1992; Curlee et al., 1970; Curlee, 1981; Ham, 1989; Kully \& Boberg, 1988; MacDonald \& Martin, 1973; Young, 1975, 1984). Most evaluations use this type of stuttering event analysis and have shown interjudge agreement to be below 60\% (Coyle \& Mallard, 1979; Curlee, 1981; Emerick, 1960; MacDonald \& Martin, 1973; Young, 1975). In addition, studies have also been completed that showed low interclinic agreement among judges (Kully \& Boberg, 1988) and low intrajudge and interjudge agreement within a particular clinic setting and across-clinics (Ingham \& Cordes, 1992).

Agreement on onset and offset of stuttering among judges who are experts in fluency was also explored (Ingham et al., 1995). The results of this study indicated high disagreement as to when and where a stuttering event takes place. In fact, according to Ingham et al. (1995), the results of their study showed "a series of interjudge agreements that raise serious questions about the reliability and validity of stuttering event onset and offset measures" (p. 323). Their study, while looking at onset and offset 
measures rather than stuttering events, still raises the question about why the identification of stuttering is so difficult. Rather than to determine why it is so difficult, the present study will test the effectiveness of using new methods to instruct those who are identifying the stuttering events.

Several other studies have attempted to improve reliability of stuttering judgments (Cordes et al., 1992; Curlee, 1981; Ingham et al., 1995; MacDonald \& Martin, 1973). In a study by Ingham et al. (1995), the authors were used as judges. Each of these individuals have strong backgrounds in the measurement, treatment and research of stuttering. Using a videolaser disc to assist in determining stuttering onset and offset by frame, the authors found that of a sample of 66 isolated stuttering events, only about half of the videoframes were agreed upon as containing stuttering by all four judges. It is truly a difficult task to identify stuttering even when using experienced judges and some of the best video technology available today. This further validates the need for new methods, such as hypermedia, which may improve reliability of stuttering identification.

Several studies seem to suggest that high intrajudge and interjudge agreement is possible (Kelly \& Conture, 1988; Zebrowski, 1991). In Zebrowski's study (1991), the judge's agreements for the presence of individual sound/syllable repetitions and sound prolongations was .96 for intrajudge and .92 for interjudge agreement as measured by a total counts index developed by Sander's (1961). This study used "videosound spectrograms" of two disfluency types and it was these disfluencies that were judged. In the study by Kelly and Conture (1988), it was reported that 
intrajudge agreements ranged from .84 to .96 and interjudge agreements from .81 to .96 . The fact that the judges could reach reasonable levels of agreement gives strong support for showing that stuttering identification can be a reliable task if and when methods are adequately controlled. The results of these two studies suggest high agreements are possible within specific teaching strategies.

\section{Basis For Improved Fluency Training}

A study by Henri (1994) study showed that speech-language pathology clinicians felt most prepared in the areas of language and articulation/phonology and least prepared in voice and fluency. Not surprisingly, clinicians stated that they felt more comfortable treating individuals who have deficits in the areas in which they have had the most experience. It is clear that education of current and future clinicians in the area of fluency is important to make each one a more well-rounded clinician. Fluency is one of many areas which could benefit from the use of hypermedia programs as an instructional tool. Several factors have led the author to select this area, not the least of which are the difficulty in stuttering identification, the need to try new methods, the lack of inservice for current clinicians, and the expressed need of these clinicians.

Another study which called for improved training in fluency was completed by Sommers and Caruso (1995). They found that inservice training was characterized by many directors of university training programs and supervisors of language services as "weak in meeting the needs of practicing clinicians for the development/enhancement of clinical 
management skills" (p. 241). These individuals felt voice and fluency were the two areas in which the individuals they worked with needed the most inservice training. Creating an alternative form of education may be effective from an instructional standpoint as well as an economic standpoint.

In addition, Sommers and Caruso (1995) looked at the American Speech-Language-Hearing Association's (ASHA) listing of inservice programs for a 5-year period from 1987-1992 and found that only 1\%, 31 of 2,771 , of all inservice programs were conducted in the area of fluency. These results coupled with the the responses of clinicians favoring more instruction in the area of fluency, make it clear that a demand exists for an instructional program which, if effective, could be used in place of inservice programs to educate current and future speech-language pathologists.

As Cordes (1994) states "the reliability of observational data may always be problematic, simply because there will always be differences among human observers" (p. 276) and advocates the use of training programs as one way to reduce differences among observers. According to to the results of Liu and Reed's (1994) study, "hypermedia technology has the potential to accommodate learners with different needs through its rich environment" (p. 432). Providing individuals with a more reliable way to perform stuttering identification is important to the field of speech communication. As stated by Lieberth and Martin (1995), we should not "abandon our search for the answers to the questions of what we can and 
should be doing with computer technology" (p. 241).

Some research looking into the use of computer technology in fluency has been completed (Strang and Meyers, 1987; Strang et al., 1989). Unfortunately, a gap in the literature still exists. Research has either targeted other topic areas in speech and hearing sciences, looked at training the client rather than instructing the clinician; or the research was done so long ago that its value for comparing hypermedia training and traditional classroom instruction methods should be questioned. Thus, the proposed research question for this thesis is: "Is hypermedia training of a stuttering identification task as effective as traditional classroom instruction methods?" 


\section{CHAPTER III}

METHOD

\section{$\underline{\text { Subjects }}$}

The twenty-eight subjects used in this study were undergraduate students in speech and hearing sciences. Subjects were selected on the criteria of their academic major being speech and hearing sciences and current enrollment in the Disorders of Communication II (SPHR 495/595) course offered during the Winter 1997 quarter from the Speech and Hearing Sciences Department at Portland State University. Subjects were randomly placed into one of two groups, the hypermedia training group or the traditional classroom instruction group. Before participating, signed permission was obtained for all subjects and a pure-tone audiometric screening at $20 \mathrm{~dB}$ HL for the frequencies of $500,1000,2000$ and $4000 \mathrm{~Hz}$ was performed. Subjects either not passing the hearing screening or not attending all three class sessions covering the stuttering identification material were allowed to participate in the study, although their data was not included in the statistical analysis of this study.

\section{Materials}

The materials traditionally used for instructing students in stuttering identification were used in instructing the Disorders of Communication Class II and were based on the methods described in the SSI-3 (Riley, 1994). Emphasis was placed on the identification of a stuttering event. Stuttering events are defined as prolongations, fixations, part word repetitions, and whole word, single syllable, repetitions. 
The class instructor and developer of the hypermedia training program were provided with an outline of instructional materials from which they were guided in the development of class lectures and hypermedia training program. These materials included:

(a) written text describing stuttering identification;

(b) definitions of key terms;

(c) audio files of spoken text;

(d) video clips of two children, two adolescents and three adults, a female and two males, which contrast stuttering vs. non-stuttering; (e) samples of stuttered speech during a repetition, prolongation, and stoppage;

(f) samples of stuttered speech by an adult male during the reading of seven sample passages.

The hypermedia program was developed with the multimedia development tool Macromedia Director 4.0. Interactivity was provided within the program for all audiovisual samples in order to provide students with the ability to type stuttered words into an input field and match their responses against those of the independent judges.

A total of eight clients from the Portland State University and Florida State University Speech and Hearing Clinics provided speech samples to be used in this research study. From this point on, the individuals providing videotaped speech samples will be referred to as 
clients and the undergraduate students, who served as judges for the hypermedia and classroom instruction modules, will be referred to as subjects. The clients were selected on the age, sex, type and severity of their stuttering in order to obtain a representative sample. The subjects used in the study were randomly assigned to either the hypermedia training or traditional classroom instruction group. This was performed by printing an alphabetical listing of all class members and assigning every other individual to one of the two groups.

The speaking samples originally recorded on videotape were made into QuickTime movies using the program Adobe Premiere 4.0. The movies were integrated with text and other multimedia components into a hypermedia training program using the multimedia development tool Macromedia Director 4.0. The multimedia computer laboratory at Portland State University was utilized to edit the component parts including audiovisual speech samples, written definitions and text of script, audio files of the script/speech samples, and input fields, for providing feedback to the user. The hypermedia training program allowed the subjects to select various audiovisual clips and make choices as to whether or not stuttering occurred during a given speech sample. Subjects had the ability to type in the words they believed were stuttered on by the client reading the passage, click a button and receive immediate feedback comparing their choices with that of the judges. Feedback was also provided to the users as to why some passages did not contain occurrences of stuttering. In addition, subjects were provided with access to on-line tutorials, which 
showed definitions for key terms.

The specific system used to edit the QuickTime movies and create the hypermedia training program was a Macintosh Power PC 8500/1200 with 16 megabytes of random access memory (RAM), and a 17" Apple Vision Monitor interfaced to a JVC Ultra Spec Drive videocassette recorder via a Sony SB-V3 AV Selector. The audiovisual samples were digitized with sound settings set for 16-bit stereo with a rate of $44.100 \mathrm{kHz}$. The video compression settings were conducted in a Cinepak High quality format, at 15 frames per second, with a data rate limit of 150 kilobytes/second to prevent the audio and video portions of the samples from being asynchronous.

Several changes were made to improve the stuttering identification program (see Table 1) used in this research study. These changes were made in order to provide subjects in the hypermedia training group with an improved version of the program which reflected the suggestions of subjects in the hypermedia group in Tetnowski and Martin's (1996) study. 
Table 1

IMPROVEMENTS TO STUTTERING IDENTIFICATION PROGRAM FOR CURRENT RESEARCH STUDY

\begin{tabular}{lll} 
& Tetnowski and Martin (1996) & Current Study \\
\cline { 2 - 3 } Testing Method & paper/pencil & within program \\
Number of Clients & 2 & 8 \\
Number of Videos & 9 & 14 \\
Size of Videos (pixels) & 160 by 120 & 240 by 180 \\
Size of Text & 12 pt. text & 14 pt. to 48 pt.
\end{tabular}

\section{Procedure}

Prior to gaining access to the hypermedia training program, those subjects assigned to the hypermedia training group received fifteen minutes of instructional classroom time from the course instructor in order to educate them on the specifics of both where and how to use the hypermedia program. During the week that subjects in the hypermedia training group were provided with access to the hypermedia program, subjects in the classroom instruction group received five hours of direct instruction, from the usual professor of the course, over three class periods. Subjects in the hypermedia training group were limited to five hours of instruction time with the hypermedia training program and were asked to log their name and time in/out whenever using the program during the one week instructional period. 
Videotape analysis was utilized as the post-testing method for both sample groups as it is the more traditional technique. All subjects were post-tested together. Each subject was randomly seated in the classroom, given a copy of the Stuttering Identification Form (Appendix A), and read the instructions at the top of the form. The instructions stated, "While observing the videotaped reading sample, mark all occurrences of stuttering by circling each stuttered word. At the conclusion, total the number of stuttered words and return this sheet to your instructor." The speech sample was an adolescent male reading a passage from the SSI-III which was provided on a VHS tape and projected on a 25" RCA Color TV. The data for those subjects not meeting the study's criteria were not included in the statistical analysis. Following the assessment phase, subjects in the hypermedia training group were surveyed for their comments using the Questionnaire For Subjects in the Hypermedia Training Group (Appendix B) and all subjects in both groups were provided with access to the stuttering identification program and videotaped copies of classroom lectures.

Analysis

Every word (unit) selected by each subject was compared against the unanimous selections of a panel of three experienced and American Speech-Language-Hearing Association (ASHA) certified speech-language pathologists (SLP's) with experience in stuttering. The decisions of the judges were based on the methods detailed in the SSI-3. Only those instances of stuttering which had unanimous agreement among all three 
judges were classified as stuttering. Comparisons were made as to whether the word (unit) was selected as stuttered/not stuttered. From this data a total number of unit-by-unit agreements for each subject and group was calculated. Comparisons by group using basic statistics such as mean, median, range and standard deviation scores were made and presented in tables. An unequal variance t-test was performed in order to determine, "Is hypermedia training of a stuttering identification task as effective as traditional classroom instruction methods?" 


\section{CHAPTER IV \\ RESULTS AND DISCUSSION}

RESULTS

The purpose of this research study was to determine if hypermedia training could be an effective method for instructing undergraduate students in stuttering identification. Specifically, the proposed research question for this thesis is: "Is hypermedia training of a stuttering identification task as effective as traditional classroom instruction methods?" The results of a recent study by Tetnowski and Martin (1996) found that there was no significani difference between the scores of students trained through hypermedia training or traditional classroom instruction methods. In order to lend support to the study completed by Tetnowski and Martin (1996), the findings in the current study must show either no significant difference between the scores of the two groups or that subjects in the hypermedia training group performed better on the stuttering identification task.

\section{Analysis}

Forty-three subjects began the study with twenty-eight completing the protocol. Subjects were not included in the study for the following reasons: not passing the hearing screening, attending all class lectures or participating in the post-testing phase of the research study. Data from the hypermedia training group $(n=13)$ and traditional classroom instruction group $(n=15)$ were analyzed in this research study. Subjects in the hypermedia group received a higher stuttering identification accuracy 
percentage of $74.17 \%$ as compared to an average of $69.21 \%$ for subjects in the traditional classroom instruction group. This is evidenced by a more accurate unit-by-unit agreement between the subject scores and that of the judges. The mean score for unit-by-unit agreements of words on the selected speech sample was 91.23 for subjects in the hypermedia training group and 85.13 for subjects in the traditional classroom instruction group out of a total of 123 possible unit-by-unit agreements. Results of this analysis are shown in Table 2.

Table 2

GROUP DATA COMPARISON

Hypermedia

Training Group
Classroom

Instruction Group
Subjects

Total Possible Agreements

Mean \# of Agreements

Median \# of Agreements

Range of Agreements

Standard Deviation

Accuracy

$t=3.89$

$\mathrm{p}=.0016^{*}$

* Significant beyond $\mathrm{p}<.05$
13

123

91.23

91

$84-102$

5.39

$74.17 \%$
123

85.13

86

$81-88$

2.30

$69.21 \%$ 
An analysis of each of the two groups is provided on Tables 3 and 4. Ten of the thirteen subjects in the hypermedia group received a stuttering identification accuracy percentage of $72 \%$ or better. Their performance on this task was as good or better than all of the subjects in the group receiving traditional classroom instruction. In addition, the stuttering identification accuracy for two of the subjects in the hypermedia group was better than $80 \%$. Overall, eighteen of the twenty-eight subjects participating in the study received a received a stuttering identification accuracy percentage of $70 \%$ or better. The lowest accuracy percentage received by any of the subjects participating in the study was $66 \%$, which is still much better than "chance" agreement of 50\%. The scores for the subjects receiving traditional classroom instruction showed less variance (7) than the scores of subjects using the hypermedia program (18). There was a seventeen word difference between the judges selections of stuttered words (48) and that of the subject choosing the highest number of stuttered words (31). Subjects in the hypermedia training group spent an average of 1 hour, 34 minutes using the hypermedia training program; the range of usage was from 55 minutes to 2 hours, 45 minutes.

There was a significant difference $(t=3.89, p=.0016)$ in the mean unit-by-unit identification of stuttered words between the two groups. There is convincing evidence to support a difference between the scores of subjects in the groups receiving hypermedia training and traditional classroom instruction at the .05 alpha level.

Based upon the analysis above, the null hypothesis: "No significant 
difference exists between the scores of students instructed through hypermedia training or through traditional classroom instruction methods" was rejected. 
Table 3

SUBJECT DATA FOR HYPERMEDIA TRAINING GROUP

\begin{tabular}{|c|c|c|c|}
\hline Subject & Stuttered Words & Agreements & Accuracy \\
\hline 101 & 22 & 93 & $76 \%$ \\
\hline 102 & 13 & 88 & $72 \%$ \\
\hline 104 & 10 & 85 & $69 \%$ \\
\hline 105 & 21 & 94 & $76 \%$ \\
\hline 107 & 9 & 84 & $68 \%$ \\
\hline 108 & 17 & 90 & $73 \%$ \\
\hline 109 & 13 & 88 & $72 \%$ \\
\hline 110 & 23 & 96 & $78 \%$ \\
\hline 111 & 17 & 92 & $75 \%$ \\
\hline 112 & 31 & 102 & $83 \%$ \\
\hline 114 & 16 & 91 & $74 \%$ \\
\hline 115 & 12 & 85 & $69 \%$ \\
\hline 116 & 23 & 98 & $80 \%$ \\
\hline
\end{tabular}


Table 4

SUBJECT DATA FOR

TRADITIONAL CLASSROOM INSTRUCTION GROUP

\begin{tabular}{|c|c|c|c|}
\hline$\underline{\text { Subject }}$ & $\underline{\text { Stuttered Words }}$ & Agreements & Accuracy \\
\hline 1 & 13 & 88 & $72 \%$ \\
\hline 2 & 11 & 86 & $70 \%$ \\
\hline 3 & 13 & 88 & $72 \%$ \\
\hline 6 & 9 & 84 & $68 \%$ \\
\hline 7 & 10 & 85 & $69 \%$ \\
\hline 8 & 10 & 85 & $69 \%$ \\
\hline 10 & 14 & 87 & $71 \%$ \\
\hline 11 & 8 & 83 & $67 \%$ \\
\hline 12 & 10 & 83 & $67 \%$ \\
\hline 13 & 12 & 87 & $71 \%$ \\
\hline 14 & 13 & 86 & $70 \%$ \\
\hline 15 & 12 & 87 & $71 \%$ \\
\hline 16 & 11 & 86 & $70 \%$ \\
\hline 17 & 8 & 81 & $66 \%$ \\
\hline 18 & 9 & 81 & $66 \%$ \\
\hline
\end{tabular}




\section{DISCUSSION}

This research study sought to determine if a significant difference exists between the scores of students instructed through hypermedia training or through traditional classroom instruction methods. Analysis of data gathered in this study indicates that there was a significant difference between the scores of subjects in the groups receiving hypermedia training versus traditional classroom instruction.

Results also appear to indicate that not only was there a significant difference in scores between the two groups, but overall, subjects in the hypermedia group actually performed better than those in the group receiving traditional classroom instruction. This occurred despite the fact that as a group, subjects in the hypermedia training group spent less time using the program than subjects in the traditional classroom instruction group did receiving in-class instruction.

Several reasons may help to explain why, overall, subjects in the hypermedia training group performed better than subjects in the group receiving traditional classroom instruction. Poor acoustics and lighting may make it difficult for some students to perform well in the traditional learning environment. When subjects have access to hypermedia training they are able to use the program when they are most alert and better able to concentrate on the material presented. Nonetheless, it is important to consider that these same results may not be obtained with groups who exhibit different selection criteria than those used in this research study. Further studies which evaluate the use of hypermedia training with 
students at a variety of institutions or with current SLP's will be important in determining further justification for the use of this hypermedia training program.

There are a couple of factors which support the results of this research study. The larger sample size used in this research study tends to account for differences between the subjects in each group. Unlike some studies which may compare the scores of the total number of stuttered words, this research study used the unit-by-unit agreement scores. Some studies have used analysis of stuttered words and have failed to account for the actions of a subject who simply circles every word they thought was stuttered, thus increasing the likelihood of more correct responses for stuttered words. Using the unit-by-unit identification method, emphasis is placed on accuracy as the selection of whether a unit (word) was not stuttered upon is as important as those units (words) that were stuttered.

It should be noted, however, that there are many factors which could affect the outcome of a study of this type. These include the instructor(s), development of the hypermedia program and the background of the subjects. For example, if an instructor lacks an extensive background in stuttering or his/her teaching methods are ineffective, students in the traditional classroom instruction group may perform poorly on the posttesting portion of this study. In addition, if the hypermedia program is not user-friendly or it does not function properly, students can become frustrated and not wish to continue using the program. Lastly, individuals with an extensive background in computer software may perform better 
than those with minimal experience in this area. Anxiety caused by unfamiliarity with computers may cause some individuals to spend more time determining how to use the program than actually learning about stuttering identification. For the undergraduate students in this study, conducted in the Speech and Hearing Sciences Department at Portland State University, with materials provided by the professor of Disorders of Communication II course, and with his assistance to the author, we find convincing evidence to support a difference between the scores of subjects in the groups receiving hypermedia training and traditional classroom instruction. 


\section{CHAPTER V \\ SUMMARY AND IMPLICATIONS}

\section{SUMMARY}

The research question addressed in this study was: "Is hypermedia training of a stuttering identification task as effective as traditional classroom teaching methods?" The results of this study can be used to assist in the determination of whether computer technology is a viable option for providing students with instruction in stuttering identification.

A recent study by Tetnowski and Martin (1996) showed no significant differences in stuttering identification between groups receiving hypermedia training and traditional classroom instruction. Tetnowski and Martin (1996) hypothesized that if computer technology could be proven through subsequent research studies to be a viable method of instructing students in stuttering identification, in-class time normally spent providing students with basic background knowledge could be used for other course topics. This would allow instructors to provide competent clinical training without sacrificing classroom time.

Subjects were recruited from an undergraduate class offered by the Speech and Hearing Sciences Department at Portland State University. All subjects were speech and hearing sciences majors. Subjects were randomly placed into a group receiving either hypermedia training or traditional classroom instruction. Data from subjects not passing a hearing screening or attending all three class sessions covering the stuttering identification material was not analyzed in this research study. Following exclusion of 
the data for some participants due to not meeting study criteria, thirteen subjects in the hypermedia group and fifteen subjects in the traditional classroom instruction group remained.

While the classroom instruction group received five hours of direct instruction over three class periods, the subjects in the hypermedia training group received fifteen minutes of instructional classroom time from the professor and were provided access to a hypermedia training program that incorporated materials like those used in classroom lectures.

Videotape analysis was utilized as the post-testing method for both sample groups. All subjects were post-tested together. After being randomly seated in the classroom, subjects observed a videotaped speech sample and marked all occurrences of stuttering.

Following completion of this task, every word (unit) selected by each subject was compared against the unanimous selections made by a panel of three experienced and ASHA certified SLP's with experience in stuttering. The decisions of the judges were based on the methods detailed in the Stuttering Severity Instrument for Children and Adults - 3rd Edition (SSI3). Comparisons were made as to whether the word (unit) was selected as stuttered/not stuttered. From this data a total number of unit-by-unit agreements for each subject and group was calculated.

An unequal variance $t$-test was performed in order to determine, "Is hypermedia training of a stuttering identification task as effective as traditional classroom instruction methods?" Results showed a significant difference between the scores of subjects trained through the hypermedia 
program and through traditional classroom instruction methods $(t=3.89$, $\mathrm{p}=.0016)$. Thus, the null hypothesis: "No significant difference exists between the scores of students instructed through hypermedia training or through traditional classroom instruction methods" was rejected.

\section{IMPLICATIONS}

Subjects stated that what they enjoyed best about using the hypermedia program was the flexibility, the ability to work at one's own pace and when they wanted. In addition, several subjects cited the numerous clips illustrating examples of what is/is not stuttering, the ability to perform practice exercises to identify stuttering, and the ability to review the material provided as many times as they wished. One subject stated that she enjoyed the feature allowing the material to be read to the listener and went on to say that the program had "great features - great examples and was very easy to use."

Subjects also provided input on what was difficult about using the program and how it could be improved in future versions. Most suggestions centered on the functioning of the program rather than its content. They stated that they spent time looking for an available computer and when one was available, it would occasionally run out of available memory, making it necessary to re-start the computer. One subject expressed the desire to have the program available in an IBM-PC version as well; it is recommended that future versions support both platforms. Several subjects stated that they did miss the ability to ask questions to clarify materials presented in the programs content. Clearly, 
instructors who use hypermedia training in place of in-class instruction must also provide students with a means of obtaining clarification on material covered. Providing the program on the Internet where users can ask questions, such as in a news group, or send electronic mail to the instructor directly, are two of many possible solutions.

In subsequent studies, it is suggested that both pre-testing and posttesting of subjects be conducted. By pre-testing it would have been possible to quantify the change in each subjects ability and one would have been able to determine the extent of each groups' progression. By post-testing without pre-testing, we are able to quantify the effect of the method. This has proven extremely informative for purposes of this study.

This current hypermedia training program was able to instruct students well enough to allow them to perform the stuttering identification task with $75 \%$ accuracy. These results are better than mere chance (50\%), or that of many previous studies (Coyle \& Mallard, 1979; Curlee, 1981; Emerick, 1960; MacDonald \& Martin, 1973; Young, 1975) which showed results below 60\%, however improvements can still be made as they are still not as high as the results ( $>80 \%)$ obtained by Kelly \& Conture (1988) and Zebrowski (1991).

Not only was an effective instructional program developed for purposes of this research study, but further steps were taken to determine its effectiveness in instructing students in a real-world environment. In both the present study and that conducted by Tetnowski and Martin (1996), hypermedia has been shown to be an effective method for educating 
students in stuttering identification. If development of effective hypermedia programs can be conducted in other areas of speech communication, such as voice disorders, aphasia and dysphagia, hypermedia may prove to be useful in these areas as well. 


\section{REFERENCES}

Cooper, J. (1990). Research directions in stuttering: Consensus and conflict. In J.A. Cooper (Ed.) Research needs in stuttering: Roadblocks and future directions. ASHA Reports, 18, 98-100.

Cordes, A. (1994). The reliability of observational data: I. Theories and methods for speech-language pathology. Iournal of Speech and Hearing Research, 37, 264-278.

Cordes, A., \& Ingham, R. (1994). The reliability of observational data: II. Issues in the identification of measurement of stuttering events. Lournal of Speech and Hearing Research, 37, 279-294.

Cordes, A., Ingham, R., Frank, P., \& Ingham, J. (1992). Time-interval analysis of intrajudge agreement for stuttering event judgments. Lournal of Speech and Hearing Research, 35, 483-494.

Coyle, M., \& Mallard, A. (1979). Word-by-word analysis of observer agreement utilizing audio and audiovisual techniques. Lournal of Fluency Disorders, 4 , 23-28.

Curlee, R., Perkins, W., \& Michael, W. Reliability of judgments of instances of stuttering. Paper presented at the Annual Convention of the American Speech and Hearing Association, New York, 1970.

Curlee, R. (1981). Observer Agreement on Disfluency and Stuttering. Lournal of Speech and Hearing Research, 24, 595-600.

Emerick, L. (1960). Extensional definition and attitude toward stuttering. Journal of Speech and Hearing Research, 3, 181-186. 
Ham, R. (1989). What are we measuring? Journal of Fluency Disorders, 14, 231-243.

Henri, B. (1994). Graduate student preparation: Tomorrow's challenge. Asha, 36(1), 43-47.

Hughes, D., Fey, M., Kertoy, M., \& Nelson, N. (1993). Computerassisted instruction for learning Developmental Sentence Scoring: An experimental comparison. Unpublished manuscript, Central Michigan University.

Hughes, D., Lehman, M., Scukanec, G., \& Tatchell, R. (1993). Computer-technology: Use in training programs. Asha, 35(9), 38-39.

Ingham, R. (1990). Commentary on Perkins (1990) and Moore and Perkins (1990): On the valid role of reliability in identifying "What is stuttering?". Lournal of Speech and Hearing Disorders, 55, 394-397.

Ingham, R., \& Cordes, A. (1992). Interclinic differences in stutteringevent counts. Lournal of Fluency Disorders, 17, 171-176.

Ingham, R., Cordes, A., Ingham, J., \& Gow, M. (1995). Identifying the onset and offset of stuttering events. Journal of Speech and Hearing Research, 38, 315-326.

Kelly, E., \& Conture, E. (1988). Acoustic and perceptual correlates of adult stutters' typical and imitated stutterings. Lournal of Fluency Disorders, 13, 233-252.

Kully, D., \& Boberg, E. (1988). An investigation of interclinic agreement in the identification of fluent and stuttered syllables. Lournal of Fluency Disorders, 13, 309-318. 
Lee, L. (1974). Developmental sentence analysis. Evanston, IL: Northwestern University Press.

Lieberth, A., \& Martin, D. (1995). Authoring and hypermedia. Language, Speech, and Hearing Services in the Schools, 26, 241-247.

Liu, M., \& Reed, W. (1994). The relationship between the learning strategies and learning styles in a hypermedia environment. Computers in Human Behavior, 10(4), 419-434.

MacArthur, C., \& Haynes, J. (1995). Student assistant for learning from text (SALT): A hypermedia reading aid. Journal of Learning Disabilities, 28(3), 150-159.

MacDonald, J., \& Martin, R. (1973). Stuttering and disfluency as two reliable and unambiguous response classes. Journal of Speech and Hearing Research, 7 595-600.

Moore, S., \& Perkins, W. (1990) Validity and reliability of judgments of authentic and simulated stuttering. Journal of Speech and Hearing Disorders, 55, 383-391.

Nicolosi, L., Harryman, E., Kresheck, J. (1996). Terminology of Communication Disorders. Baltimore, Maryland: Williams and Wilkins.

Ott-Rose, M., \& Cochran, P. (1992). Teaching action verbs with computer-controlled videodisc vs. traditional picture stimuli. The Journal for Computer Users in Speech and Hearing, 8, 15-32.

Perkins, W. (1990) What is stuttering? Lournal of Speech and Hearing Disorders, $55,370-382$.

Riley, G. (1994). Stuttering Severity Instrument For Children and 
Adults (3rd Edition). Austin; TX: PRO-ED.

Schery, T., \& O'Connor, L. (1992). The effectiveness of school-based computer language intervention with severely handicapped children. Language, Speech and Hearing Services in Schools, 23, 43-47.

Sommers, R., \& Caruso, A. (1995). Inservice training in speechlanguage pathology: Are we meeting the needs of fluency training?. American Journal of Speech-Language Pathology, 4(3), 22-28.

Strang, H., \& Meyers, S. (1987). A microcomputer simulation to evaluate and train effective intervention techniques in listing partners of preschool stutterers. Iournal of Fluency Disorders, 12, 205-215.

Strang, H., Meyers, S., \& Hall, E. (1989). Impact of microcomputer simulation training on student-clinicians' ability to effectively intervene with preschool stutters. Journal of Fluency Disorders, 14, 135-151.

Tetnowski, J., \& Martin, D. (1996, November). Hypermedia trainingof graduate students in a stuttering identification task. Presented at the annual meeting of the American Speech-Language-Hearing Association, Seattle, WA.

Tuthill, C.E. (1946). A quantitative study of extensional meaning with special reference to stuttering. Speech Monographs, 13, 81-98.

Young, M. (1975). Observer agreement for marking moments of stuttering. Journal of Speech and Hearing Research, 19, 530-540.

Young, M. (1984). Identification of stuttering and stutters. In R. Curlee \& W. Perkins (Eds.), Nature and treatment of stuttering: New directions (pp. 13-30). San Diego, CA: College-Hill. 
Zebrowski, P. (1991). Duration of the speech disfluencies of beginning stutters. Journal of Speech and Hearing Research, 34, 483-491. 


\section{APPENDIX A \\ POST-TESTING PASSAGE FOR STUTTERING IDENTIFICATION}

Sample Group (Please Circle One): Hypermedia Training/In-Class Instruction

Age: (Optional)

Sex (Please Circle One): Male/Female

Instructions: While observing the videotaped reading sample, mark all occurrences of stuttering by circling each stuttered word. At the conclusion, total the number of stuttered words and return this sheet to your instructor.

\section{OIL SUPPLY PASSAGE}

WASHINGTON-Part of the nation's future oil supply may lie within some extraordinary organisms that have been called a "third form of life." A Colorado State University microbiologist reports obtaining pure hydrocarbon that could be converted to gasoline or lubricating oils from several of the organisms. The oily substance is "energy-rich, definitely a lubricant, combustible, and isn't soluble in water," says the researcher, Thomas Tornabene. And the oil is free of air-polluting sulfur. The discovery now is only a laboratory phenomenon; any commercial application is some time away. "Right now we are concentrating on the organisms' basic mechanisms," Tornabene says. "We have two genetic engineers looking at them to find ways of getting them to grow faster and to pump oil faster."

Total Number of Stuttered Words: 


\section{APPENDIX B \\ QUESTIONNAIRE FOR SUBJECTS \\ IN THE HYPERMEDIA TRAINING GROUP}

Age:

Sex (Please Circle One): Male/Female

1. What did you enjoy most about working with the hypermedia instruction program?

2. What did you enjoy least about working with the hypermedia instruction program?

3. What improvements would you make to the program or its contents?

4. Please describe your level of experience with stuttering prior to participating in this study.

5. How much time did you spend using the program?

Additional Comments: 